\title{
Effects of Photoperiods on the Formation of Otolith Increments in the Embryonic and Larval Rainbow Trout Salmo gairdneri
}

\author{
Yasuo Mugiya* \\ (Accepted March 27, 1987)
}

\begin{abstract}
Effects of 5 different photoregimes on otolith increment formation were observed in embryonic and larval rainbow trout. Fertilized eggs were incubated within $4 \mathrm{~h}$ under photoperiods of 6-h light and 6-h dark (LD 6: 6), LD 12:12, and LD 24: 24 at about $10.3^{\circ} \mathrm{C}$. Other eggs at 1 week post-fertilization were incubated under constant light (LL) or constant darkness (DD). They were sampled at hatching and swim-up, and the number of otolith (sagitta) increments were counted under transmitted light. Sagittae first appeared as multiprimordia 1 or 2 days before the initiation of eye pigmentation and the initial increment was laid down at the eyed stage. The mean counts of otolith increments were highly correlated with each event of the light-dark cycles and expressed by the regression lines: $Y=1.96 X+29.25$ for $\operatorname{LD} 6: 6, Y=1.04 X+14.39$ for LD 12:12, and $Y=0.53 X+6.83$ for LD 24: 24 groups, where $Y$ signifies the count of increments and $X$ represents the number of days elapsed ( $X=0$ at hatching). Increments were also found under LL and $D D$, but the counts were variable for each individual. The mean rate of increment deposition from hatching to swim-up was about 1.2 and 1.4 per day in the LL and DD groups, respectively. These results indicate that photoperiod works as a potent entrainer for the rhythmic formation of otolith increments in embryonic and larval rainbow trout. Some stimuli other than photoperiod may also be capable of inducing otolith increment formation.
\end{abstract}

Teleost otoliths show microstructural growth increments consisting of a bipartite structure of calcium-dominant accretion and matrix-dominant discontinuous zones. Experimental studies on otolith growth have substantiated that otolith increments are formed on a daily basis in various marine and freshwater fish. ${ }^{1,2}$ It is also known that the rate and profile of increment formation are affected by environmental variables such as light, temperature and food.1) However, effects of these variables on increment formation are not always consistent, depending on differences of species, their ages, and experimental conditions.

Taubert and Coble, ${ }^{3)}$ and Radtke and Dean" indicated that photoperiod was the major factor controlling the periodicity of otolith increment formation in young tilapia, and larval and juvenile mummichog, respectively. Tanaka et al. ${ }^{5)}$ also found that the timing of increment formation was changeable, synchronizing with the reversed light and dark cycle in juvenile tilapia. On the other hand, Campana and Neilson ${ }^{8)}$ reported that the rate of otolith increment production was unaffected by photoperiod in the flounder of several months of age. Brothers hypothesized ${ }^{7)}$ in his short review that temperature was the predominant factor in determining the timing and intensity of otolith increment formation, with light having a minor role, and Neilson and Geen ${ }^{8)}$ partly substantiated this hypothesis by showing that a temperature cycle of a 12-h period resulted in a significantly increased rate of increment formation in juvenile chinook salmon. However, it is also well documented that daily increments are formed at a constant temperature..$^{3,4,8}$ ) Geffen ${ }^{2)}$ reported that the number of otolith increments was primarily dependent on the growth rate of individual herring and turbot larvae, and not necessarily corresponding to the daily age of the fish. She also noted that the rate of increment deposition was not a daily event in salmon embryos. ${ }^{10)}$ The shift of feeding times or starvation appears to have little effect on the alternating deposition pattern of otolith increments. ${ }^{3,5,7,11,12)}$ However, Neilson and Geen ${ }^{13)}$ found a positive influence of feeding frequency on the number of otolith increments in juvenile chinook salmon, and Campana and Neilson ${ }^{1)}$ commented that multiple daily feedings probably induced the incidence of subdaily increments.

* Faculty of Fisheries, Hokkaido University, Minato-3, Hakodate, 041 Japan（麦谷染雄：北海道大学水産学 部). 
The present study was undertaken to obtain further information on the effect of photoperiod on otolith increment formation in embryos and larvae of rainbow trout, which have a long term of yolk-sac nutrition and therefore appear to be suitable material for determining the influence of photoperiod on the deposition of otolith increments. Eggs were incubated in 5 different photoconditions at a constant temperature and developing otoliths were sampled at hatching and swim-up to count the number of increments formed.

\section{Materials and Methods}

Eggs of rainbow trout Salmo gairdneri were fertilized at Nanae Fish Culture Experimental Station, Hokkaido University, in March 1985, and transported to our laboratory within $4 \mathrm{~h}$ after fertilization. Then they were incubated under 3 different photoperiods of 6-h light and 6-h dark (LD 6: 6), LD 12: 12, and LD 24: 24 at a constant temperature of $10.3^{\circ} \mathrm{C} \pm 0.6$ (first experiment). Other developing eggs at 1 week post-fertilization (about 1 week before the appearance of otolith primordia) were obtained from the station in January 1986, and were subjected to 3 different photoregimes (LD 12: 12, constant light, LL, and constant darkness, DD) at a temperature of $10.5^{\circ} \mathrm{C}$ \pm 0.7 (second experiment). Eggs were placed in plastic-mesh baskets and incubated in aerated and filtrated water in glass aquaria (60l each) set in dark boxes with or without a $20 \mathrm{~W}$-fluorescent lamp. The aquaria were covered with glass plates on which aluminium foil sheets were partially placed to reduce the light intensity, giving about 300 lux at the water surface. Larvae were mainly sampled at hatching (30 days after fertilization) and at swim-up (15 days after hatching), measured for total length with a caliper, and kept at $-40^{\circ} \mathrm{C}$ for a few days before otoliths were dissected. Sampling in total darkness was conducted by removing one of the two baskets set in the aquarium. A change of water was not necessary throughout the experiments.

Saccular otoliths were dissected with a binocular microscope and rinsed in water on a glass microscope slide. Then they were mounted in a drop of glycerin and their long and short axes were measured with a calibrated eye-piece to the nearest $\mu \mathrm{m}$. The number of increments was directly counted with a transmitted light microscope (up to $\times 400$ ). The counting process was repeated 3 times for each otolith and the mean was adopted.
In otoliths from the LD 6: 6 group, however, increments were counted on the enlarged photomicrographs because they were too compressed to be counted directly. For otoliths sampled on the day of swim-up, it was occasionally found to be difficult to count the number of the prehatch increments because of a masking effect due to an increase in otolith thickness. In this case, increments were counted from the heavy check which was confirmed to be formed at hatching to the otolith periphery, and this count was added to the mean count of increments on the day of hatching.

In the LL and DD groups, otolith increments were counted only between each hatching check and the otolith periphery because fertilized eggs used had been kept under an uncontrolled (natural) photocondition for the first week of development and this effect (imprinted circadian episodes) may have lasted for another week or more, ${ }^{5,4)}$ affecting early increment formation in the second experiment. Nevertheless, the results of the LD 12:12 groups were essentially the same in the first and second experiments.

Subdaily increments are known to occur on some otoliths but they are distinguishable from daily increments by faint and poorly defined images. Such increments between well-defined increments were not counted, if any.

\section{Results}

Fertilized eggs in each group appeared to develop normally and most of them hatched 15 days after the initiation of eye pigmentation, which occurred 14-15 days after fertilization. Only the LL group showed a relatively high mortality rate, especially around the eyed stage. Hatched larvae stayed on the bottom of the baskets for about 15 days and then swam up.

Fish size varied among the groups (Table 1). Total length was almost the same on the day of hatching in the first experiment, but thereafter the LD 12:12 group showed rather slow growth in length. In the second experiment, incubation under LL or DD resulted in small sized-larvae at hatching, but the DD group recovered its length until swim-up (Table 1).

Saccular otoliths could first be dissected as a chain of multicores from the embryos at a stage of initiation of eye pigmentation. They grew to 150 $160 \mu \mathrm{m}$ in length in 4 or 5 days, and reached 250 $280 \mu \mathrm{m}$ at hatching (Table 2). Otoliths from the LD 24: 24 and DD groups at hatching were rather 
Table 1. Body length of rainbow trout kept under 5 different photoperiods on days of hatching and swim-up

\begin{tabular}{lcc}
\hline \multirow{2}{*}{ Group } & \multicolumn{2}{c}{ Total body length (mm) } \\
\cline { 2 - 3 } & Hatching & Swim-up \\
\hline LD 6:6 & $17.8 \pm 0.1(12)^{*}$ & $25.3 \pm 0.7(15)$ \\
LD 12:12 & $17.3 \pm 0.1(12)$ & $23.9 \pm 1.2(19)$ \\
LD 24:24 & $17.4 \pm 0.1(12)$ & $25.2 \pm 1.4(19)$ \\
& & \\
LL & $16.5 \pm 0.5(14)$ & $21.5 \pm 0.1(17)$ \\
DD & $15.7 \pm 0.5(26)$ & $24.1 \pm 0.1(25)$ \\
LD 12:12 & $17.4 \pm 0.5(16)$ & $23.7 \pm 0.1(19)$ \\
\hline * Mean \pm SD (No. of fish examined).
\end{tabular}

Table 2, Otolith size of rainbow trout kept under 5 different photoperiods on days of hatching and swim-up

\begin{tabular}{lcc}
\hline \multirow{2}{*}{ Group } & \multicolumn{2}{c}{ Otolith size (long $\times$ short diameter), } \\
\cline { 2 - 3 } & Hatching & Swim-up \\
\hline LD 6: 6 & $270 \times 144(24)^{*}$ & $385 \times 229(30)$ \\
LD 12: 12 & $266 \times 146(24)$ & $400 \times 234(34)$ \\
LD 24: 24 & $252 \times 133(24)$ & $391 \times 245(34)$ \\
& & \\
LL & $278 \times 146(27)$ & $394 \times 229(34)$ \\
DD & $259 \times 126(40)$ & $400 \times 231(39)$ \\
LD 12: 12 & $278 \times 147(32)$ & $398 \times 232(32)$ \\
\hline * Mean \pm SD (No. of otoliths examined).
\end{tabular}

- Mean \pm SD (No. of otoliths examined).

Table 3. Number of otolith increments on days of hatching and swim-up in rainbow trout kept under 5 different photoperiods

\begin{tabular}{lcc}
\hline & \multicolumn{2}{c}{ Count of increments } \\
\cline { 2 - 3 } Group & \multicolumn{2}{c}{ Days after eye pigmentation } \\
& 15 (Hatching) & 30 (Swim-up) \\
\hline LD 6: 6 & $29.3 \pm 0.8(24)^{*}$ & $58.8 \pm 2.1(28)$ \\
LD 12:12 & $14.4 \pm 0.8(23)$ & $30.1 \pm 1.3(25)$ \\
LD 24:24 & $6.8 \pm 0.5(23)$ & $14.8 \pm 0.9(30)$ \\
& & \\
LL & After hatching & $17.6 \pm 2.3(26)$ \\
DD & After hatching & $20.9 \pm 2.7(20)$ \\
LD 12:12 & $14.7 \pm 0.9(20)$ & $30.8 \pm 1.8(17)$ \\
\hline
\end{tabular}

* Mean \pm SD (No. of otoliths examined).

small in size compared to those from the other groups, but little difference was found in size on the day of swim-up. Direct correlation between body and otolith length was not necessarily found in the embryonic and larval growth of rainbow trout (Tables 1 and 2).

When observed under transmitted light, otoliths showed the alternate light and dark zones which constitute one increment unit, and the zones were most easily discerned in the postero-dorsal area. The deposition of increments appeared to start as early as 1 or 2 days after otolith differentiation (primordium formation). Four increments were already discernible in otoliths sampled from the LD 12:12 group 4 days after the beginning of eye pigmentation (Fig, 1). The mean counts of otolith increments were very closely correlated with the experimental manipulation of photocycles in the first experiment (Table 3). The LD 12: 12 group had about 15 increments at hatching (Fig. 2) and 30 increments at swim-up, corresponding to the number of days elapsed from the initiation of eye pigmentation. Thus, in this group it is evident that otolith increments were laid down on a daily basis. Relationship between the count $(Y)$ of otolith increments and the number $(X$, $X=0$ at hatching) of days elapsed is expressed as the regression line, $Y=1.04 X+14.39$ for this group. Under LD 24: 24, however, the width of each increment was considerably thick (Fig. 3) and the mean count was about half of the number of days elapsed $(Y=0.53 X+6.83)$. About 7 and 15 increments were counted on days of hatching and swim-up, respectively (Table 3 ). Under LD $6: 6$, fine increments were laid down at narrow intervals (Fig. 4) and the mean count was coincident with twice the number of days elapsed (Table 3). The regression line is $Y=1.96 X+29.25$. Thus about 30 increments had already been formed at hatching. These results indicate that the rate of increment deposition was highly synchronized with the frequency of LD cycles in the embryonic and larval otolith development of rainbow trout. Under LL and DD, otolith increments were still formed (Figs. 5 and 6 ) but the counts were variable for each individual (Table 3). The mean rate of increment deposition was more frequent than daily, and 17.6 and 20.9 increments were deposited in a 15-day period from hatching to swim-up in the LL and DD groups, respectively.

\section{Discussion}

Otoliths increments were consistently formed during the embryonic and larval growth of rainbow trout kept under 5 different photoconditions. Under LD cycles, the rate of increment formation was almost completely synchronized with the frequency of each cycle. Under LD 12:12, the initial increment was laid down as early as the eyed stage at which the otolith core grew by the fusion of several primordia. Otoliths from this 


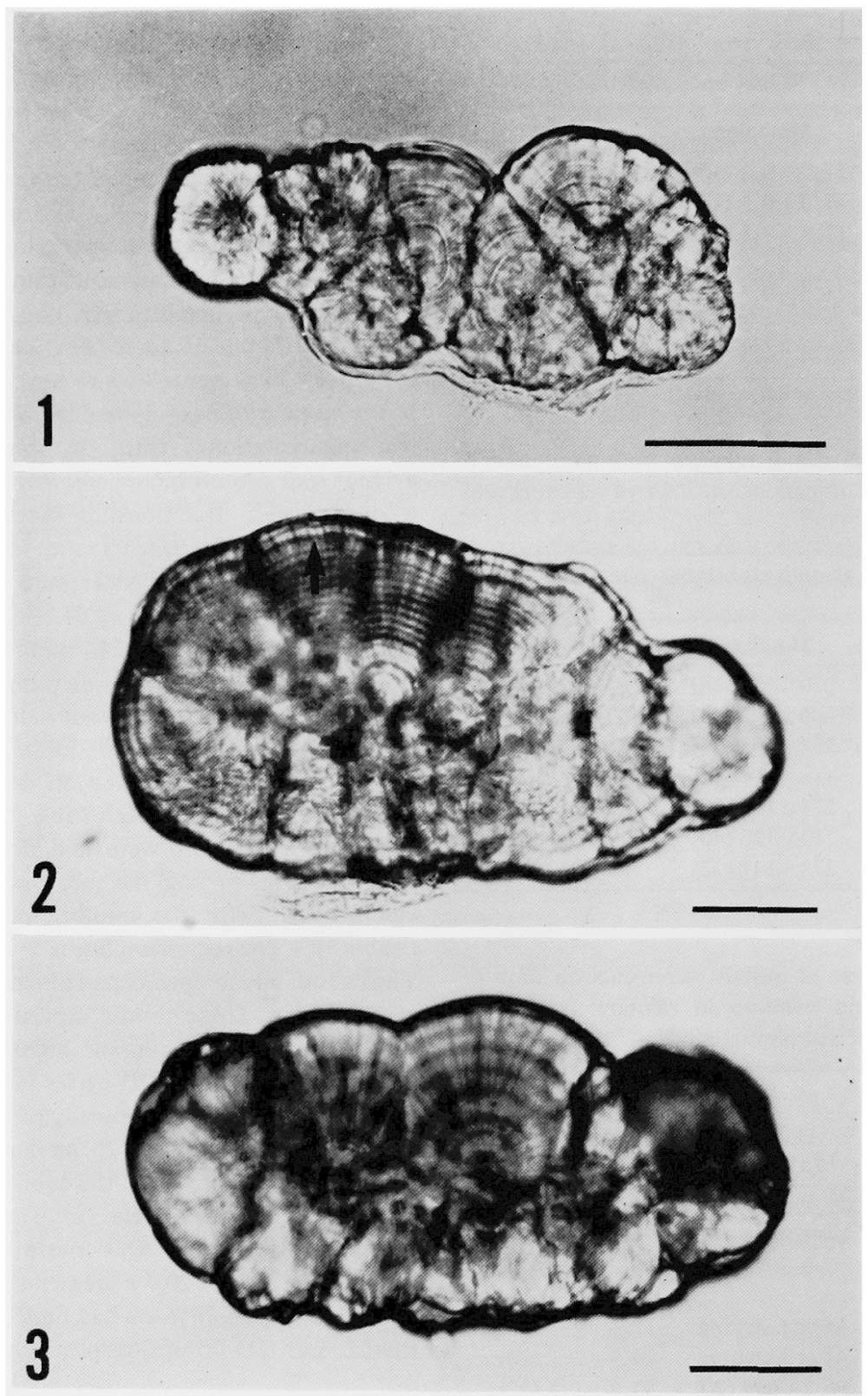

Fig. 1. Embryonic otolith (sagitta) on day 4 after the initiation of eye pigmentation in rainbow trout kept under LD 12: 12 (1st experiment). It consists of a chain of multicore and has 4 distinct increments. Scale bar is $50 \mu \mathrm{m}$.

Fig. 2. Otolith on day 2 after hatching in rainbow trout kept under LD 12:12 (1st experiment). A hatching check (arrow) is distinctly marked, and 2 increments are seen outside the check. Scale bar is $50 \mu \mathrm{m}$.

Fig. 3. Otolith on the day of hatching in rainbow trout kept under LD 24:24. Thick increments are characteristic and the mean count is about half of the number of days elapsed from the initiation of eye pigmentation. Scale bar is $50 \mu \mathrm{m}$. 


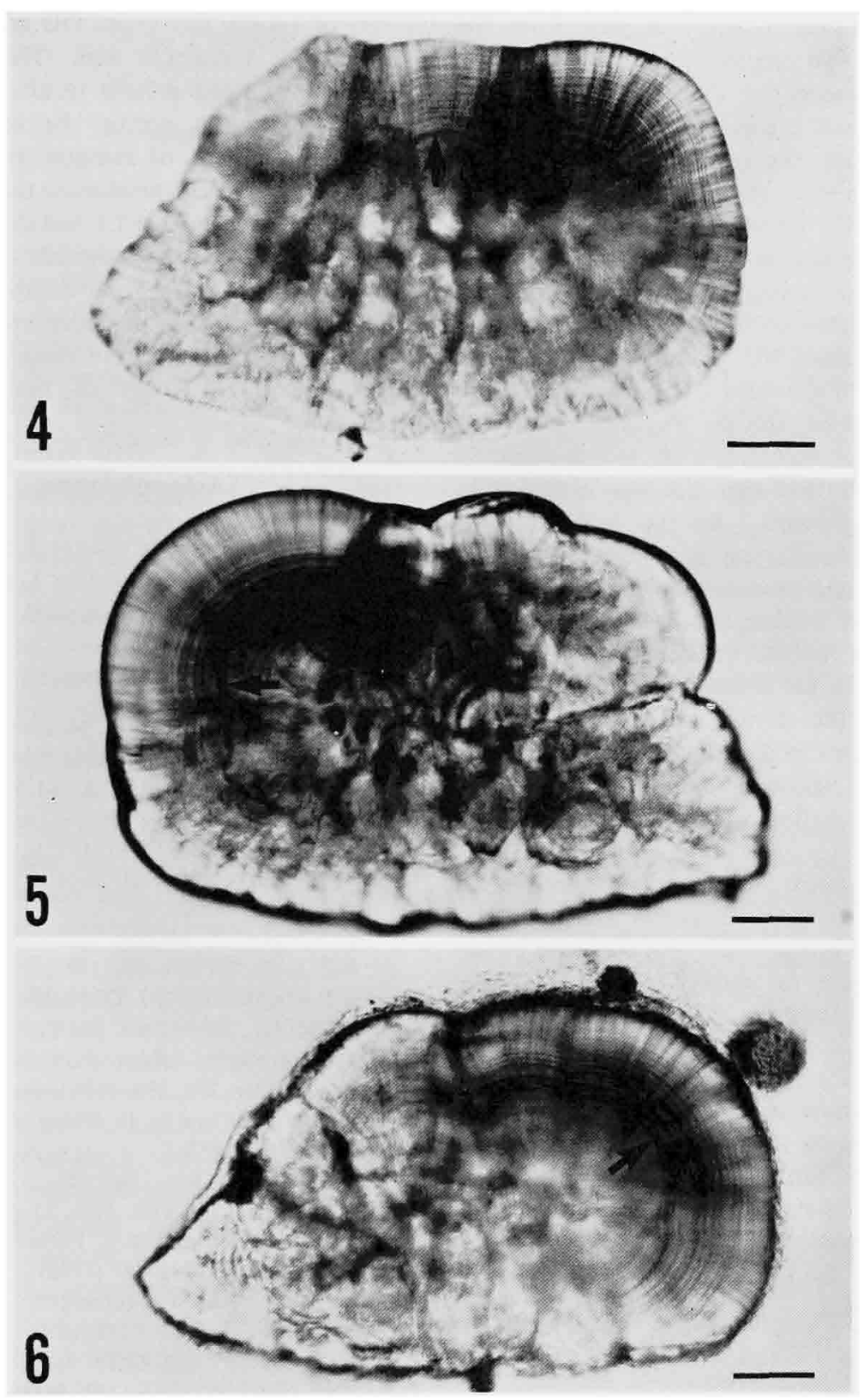

Fig. 4. Otolith on the day of swim-up in rainbow trout kept under LD 6:6. Fine increments are seen outside a hatching check (arrow), and the mean count is about twice the daily age of the fish. Prehatch increments are poorly visible because of an increase in otolith thickness. Scale bar is $50 \mu \mathrm{m}$.

Figs. 5 and 6. Otoliths on the day of swim up in rainbow trout kept under LL (5) or DD (6). Increment formation is evident, but the formation rate is variable for each individual and averages more than 1 increment per day in both groups. Arrows show a hatching check and scale bars are $50 \mu \mathrm{m}$. 
group had 14 increments at hatching, corresponding to the number of days elapsed from the initiation of eye pigmentation. Thus, these prehatch increments are daily rings in rainbow trout. This result is contrary to previous reports that the first daily ring appeared after hatching in sockeye salmon ${ }^{11}$ or after swim-up in Lepomis ${ }^{32}$ and pilchard. ${ }^{15)}$ These interspecific differences should be kept in mind when otolith increments are used for determining the daily age of fish.

The photocycles of LD 6:6 and LD 24:24 respectively induced the production of very fine and thick otolith increments, the number of which is highly correlated with the frequency of the LD cycles. The fine increments are morphologically defined so well that they are not classified as "subdaily" increments. As the fertilized eggs were incubated from a very early stage of development under a photocondition of LD 6:6 or LD $24: 24$, the only distinct stimulus they could experience would be the noncircadian rhythm of light. Therefore the stimulus may function as a zeitgeber for the noncircardian formation of otolith increments in these groups. These results indicate that a light-dark cycle is a potent integrator for the rhythmic formation of otolith increments.

Otolith increment formation occurred even under DD or LL, but its frequency was more than the number of days elapsed. Under these conditions, there were no distinct periodic environmental cues. However, the faint fluctuation of temperature, noise, vibration, and other uncontrolled variables which cannot be excluded ${ }^{1 /}$ would exist. In the absence of a distinct zeitgeber, these regular or irregular stimuli might function as a stimulus for the formation of otolith increments. Therefore, in this study it is uncertain whether or not the increment formation under DD or $\mathbf{L L}$ resulted from the free-run of an endogenous circadian rhythm.

Campana ${ }^{18)}$ found that larval and juvenile plainfin midshipman kept under $L L$ deposited otolith increments at a rate of more than 1 per day, and considered that the high increment formation resulted because some subdaily increments became prominent enough to be classified as daily, Geffen ${ }^{10)}$ reported that, when kept at $10^{\circ} \mathrm{C}$, salmon embryos deposited otolith increments at a rate of 1.8 per day under DD and at a rate of 2.1 per day under LD 6:6. These results are consistent with the present results of otolith increment formation during the embryonic and larval development of rainbow trout. In contrast, Radtke and Dean ${ }^{4)}$ showed that mummichog embryos incubated under $L L$ had the same number of otolith increments as under LD 12:12, and that those under DD had a lower number at 2 days of age. More experiments under constant photoconditions are necessary to elucidate the endogenous circadian nature of otolith increment formation.

\section{Acknowledgment}

The author thanks for Nanae Fish Culture Experimental Station, Hokkaido University, from which fertilized eggs were supplied.

\section{References}

1) S. E. Campana and J. D. Neilson: Can. J. Fish. Aquat. Sci., 42, 1014-1032 (1985).

2) C. Jones: Fish. Bull. U. S., 84, 91-103 (1986).

3) B. D. Taubert and D. W. Coble: J. Fish. Res. Board Can., 34, 332-340 (1977).

4) R. L. Radtke and J. M. Dean: Fish. Bull. U. S., 80, 201-215 (1982).

5) K. Tanaka, Y. Mugiya, and J. Yamada: Fish. Bull. U. S., 79, 459-466 (1981).

6) S. E. Campana and J. D. Neilson: Can. J. Fish. Aquat. Sci., 39, 937-942 (1982).

7) E. B. Brothers: Rapp. P.-V. Réun. Cons. Int. Explor. Mer, 178, 393-394 (1981).

8) J. D. Neilson and G. H. Geen: Fish. Bull. U.S., 83, 91-101 (1985).

9) A. J. Geffen: Mar. Biol., 71, 317-326 (1982).

10) A. J. Geffen: J. Fish. Biol., 23, 467-474 (1983).

11) S. L. Marshall and S. S. Parker: Can. J. Fish. Aquat. Sci., 39, 542-547 (1982).

12) Y. Mugiya and J. Muramatsu: Nippon Suisan Gakkaishi, 48, 1225-1232 (1982).

13) J. D. Neilson and G. H. Geen: Can. J. Fish. Aquat. Sci., 39, 1340-1347 (1982).

14) S. Inoue: Protein, Nucleic Acid and Enzyme, 27, 341-354 (1982). In Japanese.

15) P. Ré: Cybium, 7, 9-15 (1983).

16) S. E. Campana: Fish. Bull. U. S., 82, 165-177 (1984). 